\title{
Evaluation of the efficiency of cash flow management in chaotic conditions of economy structuring
}

\author{
Victoria Varenyk \\ Department of International Finance and Banking, Alfred Nobel University, Dnipropetrovsk, Ukraine
}

Email address:

Lakysant@ukr.net

\section{To cite this article:}

Victoria Varenyk. Evaluation of the Efficiency of Cash Flow Management in Chaotic Conditions of Economy Structuring. Journal of Finance and Accounting. Special Issue: Synergy of Accounting, Finance and Management in Chaotic Environment. Vol. 2, No. 6-1, 2014, pp. 37-42. doi: $10.11648 /$ j.jfa.s.2014020601.16

\begin{abstract}
The essence of the concept "cash flow management effectiveness" has been grounded, the method of comprehensive evaluation of the cash flow management effectiveness in the economy has been proposed. Practical implementation of the comprehensive assessment of the cash flow management effectiveness has been described. Three areas of effectiveness evaluation have been defined, they are: positive evaluation area, area of qualified evaluation and negative evaluation area.
\end{abstract}

Keywords: Cash Flow, Efficiency Management, Areas of Monetary Management Effectiveness,

Methods of the Effectiveness Evaluation

\section{Introduction}

Effective functioning of the national monetary system in modern conditions of instability and chaos in economic environment needs of traditional approaches to managing the cash system in national economy. That is why the deepening of theoretical, methodological and organizational principles of cash management in Ukraine's economy deserves special attention. This need is caused by methods review as for evaluating the cash flows management effectiveness of public authorities.

The question of chaotic structuring is considered by Kuznetsova S.A.

The questions of the effectiveness are considered by such scholars: O.O. Voronin, E.B. Adelseitova, I.I. Artym, N.M. Vytrenko, V.O. Zhelyabin, V.V. Zymovets, S. A. Kuznetsova, N.G. Protas, S.Yu. Naumov, N.V. Gordon, N.V. Olentsevych.

Many works are devoted to the problems of efficiency calculation, but attention is paid for production efficiency of company's effectiveness.

Management efficiency at the macro level is being studied insufficiently [3-17].

For disclosure of this issue first of all it is necessary to define the term "management effectiveness ".

Economic efficiency is an indicator that correlate received effect of the current expenditures, which caused the effect or economic resources used to obtain it [5].
In the broader sense efficiency is the ratio between the results of the business and materials, labor and financial resources that used to obtain these results [6].

In other words the efficiency of cash flaws management characterizes the productivity of public authorities activity for resolving problems concerning direction of monetary flow in the economy.

As for calculating management efficiency, in management theory, this indicator is calculated as the ratio of the effect (result) management on expenses management [17].

Efficiency generally calculated by the ratio of benefits to costs results.

The problems of complex evaluating the effectiveness of state management of cash flows are primarily the lack of relevant accountability. Annual accountability on the activities of state government bodies began to form only in 2011 due to the adoption of the Budget Code of Ukraine.

\section{Main Body}

Under the method of complex estimation cash flow management effectiveness in the economy should be understood as a system of research of the actual deviations in cash flow from planned with the purpose of assessment of conformity the actual data to planning data. Using this method allows to make conclusions about the activities of management structures and effectiveness of their activity. To 
achieve this goal it is necessary to collect the planned and actual indicators of the analyzed structures for a long period of activity to identify weaknesses and calculating the efficiency of decisions management.

A comprehensive evaluation of the cash flows effectiveness is possible due to deviation methods of planned indicators from actual for groups of indicators that distinguished, assigning these groups of number and calculation indicator of the effectiveness for all groups.

Practical implementation of the comprehensive assessment of monetary flows management efficiency is carried out in the process of evaluating the effectiveness of integrated cash management authorities of Ukraine.

According to the algorithm for evaluating the comprehensive monetary flows management efficiency in Ukraine is conducted on 9 th stages and in three complex indicators.

The mechanism of ccomprehensive assessment of cash flows management efficiency is carried out by the following stages:

Stage 1. Collecting information on monetary flow.

Stage 2. Separation of groups of efficiency indicators of cash flows in the economy.

Stage 3. Assign each group the indicators of cash flows corresponding weight.

Stage 4. Assign each indicator a number.

Stage 5. Calculation of each group efficiency indicators of cash flows.

Stage 6 Calculation the total efficiency indicator of cash flow.

Table 1. The distribution of groups of indicators' cash flow management efficiency specific gravity in the economy of Ukraine

\begin{tabular}{|c|c|c|}
\hline Group № & Group name & Group specific gravity (Wi) percentage \\
\hline \multicolumn{3}{|c|}{ Segment of private finance } \\
\hline 1 & Cash flows from operating activities & $\mathrm{A}(\%)$ \\
\hline 2 & Cash flows from financing activities & $\mathrm{B}(\%)$ \\
\hline 3 & Cash flows from investing activities & $\mathrm{C}(\%)$ \\
\hline 4 & Accounts payable & $\mathrm{D}(\%)$ \\
\hline 5 & Accounts receivable & $\mathrm{E}(\%)$ \\
\hline$\ldots$ & $\ldots$ & \\
\hline $\mathrm{n}$ & Equity & $\mathrm{G}(\%)$ \\
\hline Total & & $100 \%$ \\
\hline \multicolumn{3}{|c|}{ Public finance segment } \\
\hline 1 & State budget revenues & $\mathrm{A}(\%)$ \\
\hline 2 & State Budget Expenditures & $\mathrm{B}(\%)$ \\
\hline 3 & Public debt & $\mathrm{C}(\%)$ \\
\hline 4 & Exports of goods (works, services) & $\mathrm{D}(\%)$ \\
\hline 5 & Imports of goods (works, services) & $\mathrm{E}(\%)$ \\
\hline ... & $\ldots$ & \\
\hline $\mathrm{n}$ & Government loans & $\mathrm{G}(\%)$ \\
\hline Total & & $100 \%$ \\
\hline \multicolumn{3}{|c|}{ International finance segment } \\
\hline 1 & Debt on loans to international organizations, economic development & $\mathrm{A}(\%)$ \\
\hline 2 & Debt on loans to foreign authorities & $\mathrm{B}(\%)$ \\
\hline 3 & Debt on loans to foreign commercial banks & $\mathrm{C}(\%)$ \\
\hline$\ldots$ & $\ldots$ & \\
\hline $\mathrm{n}$ & Debt, not included in other categories & $\mathrm{D}(\%)$ \\
\hline Total & & $100 \%$ \\
\hline
\end{tabular}

Stage 4. Assign each indicator number.
Stage 7 Data analysis on the effectiveness of cash flow management.

Stage 8 Recommendations affirmation for improving the cash flow management efficiency.

Stage 9 Control over recommendations implementation for improving cash flow management efficiency.

Let us consider each stage in more detail.

Stage 1. Collect information on monetary flow. At this stage users collected all the necessary information for calculating the efficiency of cash flows management.

In the process of collection information it is necessary to have data on planned and actual time. In addition, information for each subject of management, which is estimated will have varied character.

Stage 2. Separation of groups of efficiency indicators of monetary flows in the economy. The purpose of this stage is the groups indicators formation which allows to calculate the cash flow management efficiency in the economy into the following segments: private, public and international. This stage is very important because the incorrectly dedicated indicators give an incorrect effectiveness assessment.

Stage 3. Assign each group of indicators of cash flows corresponding weight on the basis that the sum of weights of all indicators is $100 \%$. For a complex consideration of each of the evaluated groups influence on the e cash flow management efficiency in general, each group of indicators is given individual weights in the final indicator of the efficiency. The appropriation of weight of group efficiency indicators monetary flows in the economy of Ukraine for different segments are presented in Table 1.

\footnotetext{
According to the method of indicators calculation of be divided into three groups:
}

Nikishin A.I. [1] for assigning efficiency indicators, they can 
1 Index qualitative or quantitative, that tends to increase.

$$
\Delta I=\frac{I_{\text {plan }}-I_{\text {actual }}}{I_{\text {plan }}} \cdot 100 \%,
$$

where $\Delta \mathrm{I}$ - coefficient of deviation of the actual value of the efficiency indicator from planned value, $\%$.

$\mathrm{I}_{\text {actual }}$ - actually achieved value efficiency indicator (in index units).

$\mathrm{I}_{\text {plan }}$ - planned (target) value efficiency indicator (in index units).

Depending on the value of the coefficient of deviation of the actual value of the indicator of the effectiveness planned value $(\Delta \mathrm{I})$, it is assigned a certain number of points $(\mathrm{Pi})$ on a scale from 0 (minimum efficiency) to 20 (maximum efficiency).

2 Indicator qualitative or quantitative, that is close to zero.

Calculated as follows:

- based on statistical historical data calculated maximum indicator value worse $\left(\mathrm{I}_{\max }\right)$;

- on the basis of this negative coefficient is calculated deviation of the actual value of the indicator of the effectiveness planned value based on the maximum negative value of the indicator:

$$
\Delta I_{\max }=\left(1-\frac{I_{\max }-I_{\phi c e e p o}}{I_{\max }}\right) \cdot 100 \%,
$$

where $\Delta \mathrm{I}_{\max }-$ coefficient of deviation of the actual value of the efficiency indicator from planned values based on the most inefficient index value (for monetary receipts) and minimally ineffective (for spending money), $\%$.

$\mathrm{I}_{\text {actual }}$ - actually achieved value of efficiency indicator (in index units);

$\mathrm{I}_{\max }$ - achieved maximum negative value of the index (in units indicator).

Depending on the value of the coefficient of deviation of the actual value of the efficiency indicator from planned value based on the maximum negative value of the index (Imax), this indicator is assigned a certain number of points ( $\mathrm{Pi}$ ) of 0 to 20.

\section{Binary indicator.}

The indicator is measured with the answer "Yes" or "No", the only possible deviation the actual indicator from planned value is $100 \%$ (planned value is "yes", but actual value is "no"). Indicator is assigned or 20 points (planned value reached) or 0 points (value not reached).

Stage 5. Calculation of the efficiency of each group indicators of monetary flows.

At this stage, the calculation efficiency based on values assigned numbers each efficiency indicator of group in which indicators are included.

To calculate we use the formulas [1] :

$$
E P_{N}=\sum_{1}^{n}\left(P_{i} \cdot W_{i}\right)
$$

where $\mathrm{EP}_{\mathrm{N}}$ - point value of the coefficient of efficiency of group N;

$\mathrm{P} i$ - point value of the index I;

$\mathrm{W}_{\mathrm{i}}$ - weight of index I in the group, \%;

$\mathrm{n}$ - number of indicators.

To assess the effectiveness of the indicators, the actual value of final index of efficiency $\left(\mathrm{EP}_{\mathrm{N}-\max }\right)$ is compared with its maximum possible value, which is calculated on the assumption that each indicator can be awarded the maximum 20 points [237]:

$$
E P_{N-\max }=\sum_{1}^{n}\left(20 \cdot W_{i}\right)
$$

where $\mathrm{EP}_{\mathrm{N}-\max }$ - maximum point value of the coefficient of efficiency of group $\mathrm{N}$;

$\mathrm{W}_{\mathrm{i}}$ - weight of index I in the group, \%;

$\mathrm{n}$ - number of indicators.

The efficiency calculation of group carried out by comparing number of efficiency coefficient $\left(\mathrm{EP}_{\mathrm{N}}\right)$ and its maximum possible value $\left(\mathrm{EP}_{\mathrm{N}-\max }\right)[1]$ :

$$
E_{i}=\frac{E P_{i}}{E P_{i-\max }} \cdot 100,
$$

where $E_{i}$ - effectiveness of i-th group, \%;

$E P_{i}$ - point value of the efficiency coefficient of $i$-th group;

$\mathrm{EP}_{\mathrm{i} \text {-max }}$ - maximum point value of the efficiency coefficient of i-th group.

Stage 6 Calculation the indicator of the total efficiency of cash flow.

Final efficiency indicator of monetary flows is calculated based on the weight values efficiency indexes of each group of indicators that were assigned to stage 3 [1]:

$$
E T=\sum_{A}^{n}\left(E_{i} \cdot W_{i}\right)
$$

where ET - total efficiency indicator of cash flows, \%;

$\mathrm{i}$ - $\mathrm{i}$-th group;

$E_{i}-$ effectiveness of $i$-th group, \%;

$\mathrm{W}_{\mathrm{i}}$ - weight of $\mathrm{i}$-th group in the final indicator of the effectiveness, \%;

The level of efficiency cash flows management of the system as a whole is determined based on its value: unsatisfactory level - $0-25 \%$; low level - $25-45 \%$; satisfactory level - 45-60\%; average level - 60-80\%; high level - 80-100\%.

Stage 7 Data analysis on the cash flow management effectiveness. At this stage, the data for the final indicator of the effectiveness analyzes. If the result is positive and satisfies the analyst, then the calculation efficiency is over. If the result is not satisfying and there is a necessity in conducting calculation the efficiency once again, the analyst either is returned to the second stage of the selection efficiency indexes and calculates again or goes to stage 8 .

Stage 8 Recommendations affirmation for improving the cash flow management efficiency. At this stage is the development and approval of directions to improve the efficiency monetary flow management and putting them into 
action

Stage 9 Control over execution of recommendations for improving cash flow management effectiveness. At this stage, the control over the implementation of directions to improve the cash flow management effectiveness..

\section{Results and Discussion}

Consider the practical implementation of a comprehensive evaluation of the cash flow management effectiveness of Ukrainian government for previous steps.

Stage 1. Collecting information on cash flow.

At this stage, statistical information on the structure of revenues and expenditures of the State Budget of Ukraine for the period from 2000 to 2013 is used. The basis of the calculations were taken planned and actual data. The main sources of information were the State Treasury of Ukraine reports on budget execution for the period from 2000 to 2013 [2].

Stage 2. Separation of groups of efficiency indicators of cash flows in the economy.

Groups of indicators were formed as follows:

Group 1. Input monetary flow of the state budget: tax revenues; non-tax revenues; income from capital transactions; trust funds; transfers.

Group 2. Output cash flow of the state budget: general government functions; defense; public order, security and judicial authorities; economic activity; environmental protection; housing and communal services; health care; spiritual and physical development; education; social protection and social security; interbudgetary transfers.

Stage 3. Assign each group of indicators of cash flows corresponding weight on the basis that the sum of weights of all indicators is $100 \%$ Table 2 . The weight was divided $50 \%$ to $50 \%$ because of Ukraine state budget revenues and expenditures are interrelated.

Table 2. Weight of group of cash flow efficiency indexes of the national economy Distribution

\begin{tabular}{lll}
\hline Groups & Group name & Group weight (Wi) in percentage \\
\hline A & $\begin{array}{l}\text { Input monetary flow } \\
\text { of the state budget }\end{array}$ & $50 \%$ \\
B & $\begin{array}{l}\text { Output monetary flow } \\
\text { of the state budget }\end{array}$ & $50 \%$ \\
Total & & $100 \%$ \\
\hline
\end{tabular}

Stage 4. Assignment of each indicator number.. Assignment points was for each article of input and output monetary flow depending on how are performed the actual values in comparison with the planned.

Stage 5. Efficiency calculation of each group indicators of cash flows is in three complex indicators using EXCEL.

5.1. Calculation of cash flows management efficiency, according to the first complex indicator qualitative or quantitative, that tends to increase.

The calculation is performed in the following steps:

1 Determination of weight (Wi) of each group of indicators, $\%$.

2 The calculation EPA and EPB point value of the coefficient of efficiency of group A and B;

3 EPA-max, EPB-max - maximum point value of the coefficient of efficiency of group $A$ and $B$;

4 EA, EB - effectiveness of group A and B, \%;

The final indicator calculation of the cash flows management effectiveness for the first complex indicator shown in Table 3.

Thus, the final calculation of cash flows management effectiveness of Ukraine shows that the cash flows management effectiveness in the country has a satisfactory level in almost all years, as covered in the interval of $45-60 \%$ and in 2012-2013 tends to decrease.

5.2. Efficiency calculation of cash flows management for second complex indicator - a qualitative or quantitative, that approaching to zero.

The calculation is performed in the following steps:

1 First, based on statistical data for prior periods calculated the maximum negative value of the indicator (Imax).

2 Based on the selected negative values calculated the coefficient of deviation of the actual value of the indicator of the effectiveness from planned value based on the maximum negative value of the indicator $\Delta \mathrm{Imax}$ and assigned point values.

3 EPA-max, EPB-max - maximum point value of the coefficient of efficiency of group A and B;

4 EA, EB - effectiveness of group A and B, \%;

The calculation of the final indicator of the cash flows management effectiveness for the second complex indicator shown in Table 4.

The cash flows management effectiveness of Ukraine in accordance appropriation points when the indicator qualitative or quantitative, that approaching to zero shows that the cash flows management effectiveness included in the interval from $0-25 \%$, which indicates the unsatisfactory level of efficiency.

5.3. Calculation of the cash flows management effectiveness for the third indicator - binary.

Table 3. Coefficients of cash flows management effectiveness calculation for the first complex indicator, qualitative or quantitative, that tends to increase.

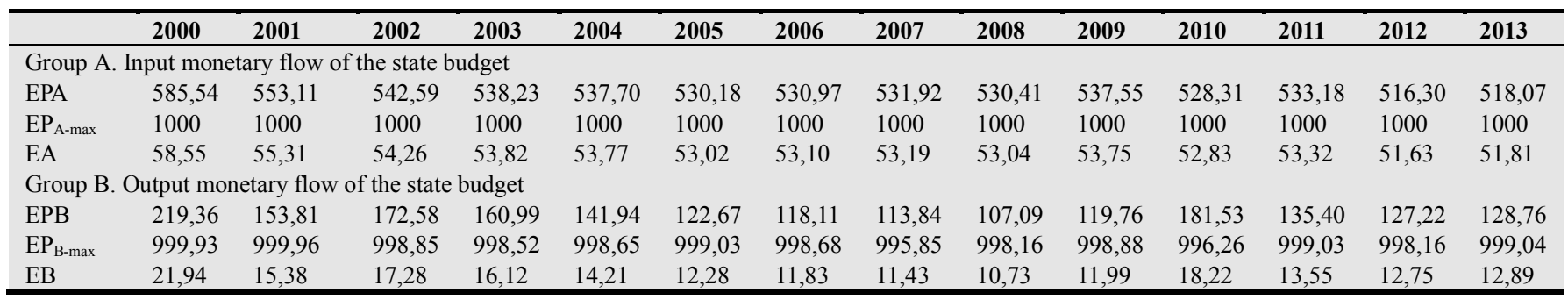


The method of calculation differs from the previous assignment numbers. Points are awarded in accordance measurement of answers "Yes" / "No", the only possible. Indicator assigned or 20 points (planned value reached) or 0 points (value not reached).

The calculation of the final indicator of the cash flows management effectiveness for the third complex indicator is shown in Table 5.

Table 4. Coefficients of cash flows management effectiveness calculation for the second complex indicator when indicator in quality or quantity that approaching to zero

\begin{tabular}{|c|c|c|c|c|c|c|c|c|c|c|c|c|c|c|}
\hline & 2000 & 2001 & 2002 & 2003 & 2004 & 2005 & 2006 & 2007 & 2008 & 2009 & 2010 & 2011 & 2012 & 2013 \\
\hline \multicolumn{15}{|c|}{ Group A. Input monetary flow of the state budget } \\
\hline EPA & 0,00 & 0,00 & 0,00 & 0,00 & 0,00 & 0,00 & 0,00 & 0,00 & 0,00 & 0,00 & 0,00 & 0,00 & 0,00 & 0,00 \\
\hline $\mathrm{EP}_{\mathrm{A}-\max }$ & 1000 & 1000 & 1000 & 1000 & 1000 & 1000 & 1000 & 1000 & 1000 & 1000 & 1000 & 1000 & 1000 & 1000 \\
\hline EA & 0,00 & 0,00 & 0,00 & 0,00 & 0,00 & 0,00 & 0,00 & 0,00 & 0,00 & 0,00 & 0,00 & 0,00 & 0,00 & 0,00 \\
\hline \multicolumn{15}{|c|}{ Group B. Output monetary flow of the state budget } \\
\hline $\mathrm{EP}_{\mathrm{B}}$ & 219,36 & 153,81 & 172,58 & 160,99 & 141,94 & 122,67 & 118,11 & 113,84 & 107,09 & 119,76 & 181,53 & 135,40 & 127,22 & 128,76 \\
\hline $\mathrm{EP}_{\mathrm{B}-\max }$ & 999,93 & 999,96 & 998,85 & 998,52 & 998,65 & 999,03 & 998,68 & 995,85 & 998,16 & 998,88 & 996,26 & 999,03 & 998,16 & 999,04 \\
\hline EB & 21,94 & 15,38 & 17,28 & 16,12 & 14,21 & 12,28 & 11,83 & 11,43 & 10,73 & 11,99 & 18,22 & 13,55 & 12,75 & 12,89 \\
\hline
\end{tabular}

Table 5. Coefficients of cash flows management effectiveness calculation for the third complex indicator as a binary indicator

\begin{tabular}{|c|c|c|c|c|c|c|c|c|c|c|c|c|c|c|}
\hline & 2000 & 2001 & 2002 & 2003 & 2004 & 2005 & 2006 & 2007 & 2008 & 2009 & 2010 & 2011 & 2012 & 2013 \\
\hline \multicolumn{15}{|c|}{ Group A. Input monetary flow of the state budget } \\
\hline EPA & 460,10 & 989,27 & 651,20 & 0,00 & 0,00 & 975,15 & 271,92 & 291,30 & 733,79 & 702,96 & 783,22 & 0,00 & 141,07 & 1,53 \\
\hline $\mathrm{EP}_{\mathrm{A}-\max }$ & 1000 & 1000 & 1000 & 1000 & 1000 & 1000 & 1000 & 1000 & 1000 & 1000 & 1000 & 1000 & 1000 & 1000 \\
\hline EA & 46,01 & 98,93 & 65,12 & 0,00 & 0,00 & 97,51 & 27,19 & 29,13 & 73,38 & 70,30 & 78,32 & 0,00 & 14,11 & 0,15 \\
\hline \multicolumn{15}{|c|}{ Group B. Output monetary flow of the state budget } \\
\hline EPB & 566,76 & 0,00 & 276,59 & 583,05 & 211,63 & 0,00 & 0,00 & 0,00 & 0,00 & 0,00 & 126,52 & 178,72 & 0,00 & 0,00 \\
\hline $\mathrm{EP}_{\mathrm{B}-\max }$ & 999,93 & 999,96 & 998,85 & 998,52 & 998,65 & 999,03 & 998,68 & 995,85 & 998,16 & 998,88 & 996,26 & 998,64 & 998,16 & 999,04 \\
\hline
\end{tabular}

Thus, according to the calculation of the cash flows management effectiveness of Ukraine in accordance the third method - binary indicator, observed that the cash flows management effectiveness is in 2000, in 2011 - a satisfactory level of management efficiency, 2001, 2005, 2008-2010, 2012-2013 - unsatisfactory level of efficiency management, 2002, 2006 - 2007 - low level efficiency, 2003 - 2004 average level cash flows management effectiveness.

Thus, according to cash flows management effectiveness calculation of Ukraine in according to the third complex indicator is observed that the cash flows management effectiveness is chaotic, but 2012-2013 represents the worst level of management, the value of index tend to zero.

Stage 6 Calculation the indicator of the total efficiency of monetary flow.

Total indicator of efficiency on three complex indicators are given in Table 6.

Table 6. Values of the final indicator of cash flows management efficiency of Ukraine's economy by different methods of calculation

\begin{tabular}{|c|c|c|c|c|c|c|c|c|c|c|c|c|c|c|}
\hline & 2000 & 2001 & 2002 & 2003 & 2004 & 2005 & 2006 & 2007 & 2008 & 2009 & 2010 & 2011 & 2012 & 2013 \\
\hline ET1 & 60,85 & 56,49 & 54,20 & 54,99 & 54,58 & 51,96 & 52,21 & 52,84 & 52,06 & 51,93 & 53,46 & 52,48 & 25,82 & 25,90 \\
\hline ET2 & 10,97 & 7,69 & 8,64 & 8,06 & 7,11 & 6,14 & 5,91 & 5,72 & 5,36 & 5,99 & 9,11 & 6,78 & 6,37 & 6,44 \\
\hline ET3 & 51,34 & 0,54 & 31,29 & 79,20 & 60,60 & 1,24 & 36,40 & 35,44 & 13,31 & 14,85 & 10,84 & 48,43 & 7,05 & 0,08 \\
\hline
\end{tabular}

According to the data analysis conducted by three complex indicators we may form the final result of assess and identify zones for evaluating the cash flows management effectiveness in the economy of Ukraine.

Thus, the Area, the range of which is included in the highest efficiency interval $(80$ - 100) - denoted as positive evaluation zone. Area, the range of which is included in the average efficiency interval $(40$ - 79) - denoted as zone a qualified evaluation. Area, the range of which is included in the lowest efficiency interval (0 - 39) - denoted as negative evaluation area. The results of efficiency calculation of each indicator and areas of estimate are presented in Fig. 1.

\section{Conclusions}

The methods of comprehensive evaluation of cash flows management effectiveness in the economy is a system of research deviations of actual data on cash flows from planned to assess compliance evidence-planned. Indicated method can be used by various subjects of management. The method allows making conclusions about the activities of management structures and evaluating their effectiveness. According to the analysis conducted by three complex indicators have revealed that the effectiveness monetary flows management of Ukraine for 2000-2013 was very low.

For the first indicator the level of efficiency was satisfactory, for the second was low and for third was unsatisfactory. Thus, for any of the total final results monetary flows management in the domestic economy is not reached high levels. The maximum assessment that have been received for Ukraine for 2000 - 2013 is a satisfactory level of efficiency, which tend to reduce. 
Thus, the use of different methods of estimation confirms the single trend of low level of cash flows management effectiveness in the economy of Ukraine.

It is necessary to develop a system of monitoring and control potency (efficiency) of public authorities. Organization and implementation of monitoring individuals and entities to avoid tax evasion.

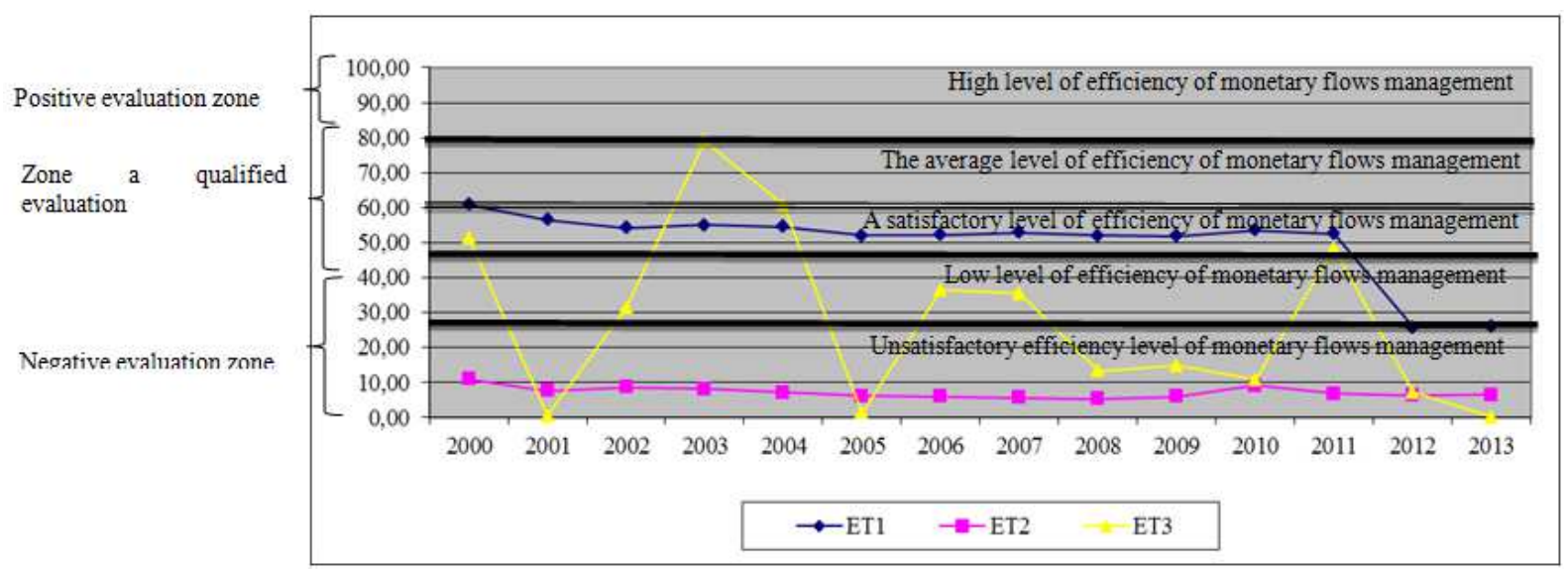

Figure 1. The final indicator of cash flows management effectiveness calculation of the Ukraine economy by different methods of calculation

\section{References}

[1] A.I Nikishin, "Development of a comprehensive system of evaluation of the effectiveness of the regional government," Institute for Public Finance Reform, Moscow, 2007, pp. 1-28.

[2] Reporting on budget execution for $2000-2013$, Available at: http://www.treasury.gov.ua/main/uk/doccatalog/list?currDir=1 46477.

[3] S. Kuznetsova, "The transformation of accounting systems in the chaotic economy structuring: The synergetic approach", Risk and Decision Analysis, 2011, vol.2, no3, pp.151-160.

[4] S.A. Kuznetsova, V.M. Varenyk, "The paradigm monetary flows management in chaotic structured economy", Academic Review, 2012, vol 1, pp. 63-68.

[5] O.O. Voronin. Determine the type of functional dependence between the efficiency of production and its factors, Available at: http://www.ief.org.ua/Arjiv_ET/Voronin307.pdf.

[6] Evaluating the effectiveness of the changes and innovations in the system of management, Available at: http://dsam.donetsk.ua/?p=588.

[7] E.B. Adelseitova, "Forming an effective mechanism to regulate the national economy", Crimean Engineering and Pedagogical University, Simferopol, 2009, pp. 1- 20.

[8] I.I. Artym, "Evaluating the effectiveness of management in government executive (for example, district state administrations)," Lviv Regional Institute of Public Administration, 2004, pp. 1- 21.
[9] N.M. Vitrenko. Social Infrastructure of Ukraine: Assessment of the level and development prospects, Kyiv: Sciences Dumka, 1993, 144.

[10] V.A. Zhelyabin. Evaluating the effectiveness of public administration according to the criteria of the financial security of Ukraine, Available at: http://zgia.zp.ua/gazeta/VISNIK_37_18.pdf.

[11] V.V. Zymovets. State financial policy of economic development, National Academy of Sciences of Ukraine, Institute of Economics and Forecasting, Kyiv, 2010, 356.

[12] D.M. Pavlov. Effectiveness of the system of public administration: concepts, conditions and evaluation criteria, Available at: http://www.naiau.kiev.ua/tslc/pages/biblio/visnik/2003_1/_zmi st_06/pavlov.htm.

[13] N.G. Protas. "Evaluating the effectiveness of the use of the factors of development in the regions", Samara State University of Economics, Barnaul, 2011, pp. 1- 23.

[14] O.B. Babich "The effectiveness of the functioning of public administration and local self-government through the introduction of corporate culture: Author. Dissertation", Kharkiv Regional Institute of Public Administration, Kharkiv, 2005, pp. 1- 22.

[15] C.Y. Naumov, System of state management, Available at: http://lib.rus.ec/b/214616/read.

[16] M.V. Gordon, N.V. Olentsevich. Efficiency of state management of the economy in Ukraine: problems of assessment, Available at: http://www.donntu.edu.ua.

[17] Management theory,
http://books.efaculty.kiev.ua/men/6/t11/2.html. 